\title{
DYNAMIC RESEARCH OF THE ROPE ELECTRIC DRIVES
}

\author{
Iryna Voloshyna (Author 1) ${ }^{1}$, Volodymyr Moroz(Author 2) ${ }^{2}$
}

1. EKS Department, Lviv Polytechnic National University, Ukraine, Lviv, E-mail: voloshyna98iryna@gmail.com

2. EKS Department, Lviv Polytechnic National University, Ukraine, Lviv, E-mail: volodymyr.i.moroz@lpnu.ua

\begin{abstract}
This article surveys an analysis of dynamic processes of the rope electric drives such as hoisting-and-transport mechanisms using computer simulation, considering the effect of sagging of the rope. A comparison of the accuracy of the obtained computer models with and without the nonlinearity of its elasticity coefficient is considered. Structural models with the use the libraries of MATLAB + Simulink mathematical program proposed to solve this problem.
\end{abstract}

Keywords - computer simulation, rope electric drive, structure modeling, sagging rope model.

\section{Introduction}

The analysis of the nonlinear systems' dynamics is a rather complicated task in the research of control systems of electromechanical objects. In this case, according to the authors, it is promising to use modern means of computer simulation, which, however, requires solving problems of creating mathematical and computer models of investigated objects for this purpose. In computer simulations, in many cases, they try to avoid additional complication of models because of an increase in the order of the equations system that describe the behavior of the object, and taking into account nonlinearities of the investigated object. It is rationally, as practice shows that, the complication of the model of the investigated system has its rational limits, above which the effect of improving accuracy is negligible. This phenomenon is due to a number of factors, which described in the famous scientific and technical sources, as discussed below.

\section{Analysis of previous studies and publications}

Any computer model is a behavior approximation of the object being studied. As is known from the applied mathematics, the accuracy of approximation virtually ceases to increase with an increase in its order above the $3^{\text {rd }}-4^{\text {th }}$, while the numerical stability of the approximants is reduced [1]. This is confirmed in [2], [3], where the ineffectiveness of approximations above the $3-4^{\text {th }}$ order in the problems of modeling and processing of information is shown. Thus, it is known that the approximation by polynomials above the $5^{\text {th }}$ order in practice is not used as a result of the increase in the variability of approximation and the reduction of its numerical stability [4-6]. Moreover, in [7] it is shown that the $5^{\text {th }}$-order linear model provides practically the same accuracy of the reproduction of dynamic processes as the non-linear model of the $11^{\text {th }}$ order. That is why it is an interesting task to study the practical impact of the complication of the computer model on the accuracy of reproduction of dynamic processes.

The complications of models are often avoided during modeling of excavating electric drives, which are traditionally characterized by a rather complicated behavior due to the presence of both high order equations describing the control system and the electromechanical part, and the presence of smooth and hard nonlinearities. Taking into account such nonlinearities as the backlash in mechanical transmissions, the characteristics of the magnetization of electric 
apparatuses and machines, allows us to obtain more adequate reproduction of the behavior of real objects in a computer model. However, it is immediately noticeably complicated both by the model itself and by the numerical method's decision-making process due to "jamming" on discontinuous sections of nonlinearities [4], [6].

The complexity of the formation of nonlinear models, in particular, in the excavator electric motor, is confirmed by the lack of publications, which addresses the problem of taking into account such a significant nonlinearity as the sagging of ropes in the drives of digging mechanisms of powerful dragline excavators. This applies equally to older publications (for example, [8], [9]), and modern scientific research [10], [11]. Even the emergence of such powerful simulation tools like MATLAB + Simulink that used in the work mentioned, did not lead to more advanced models that take into account the mentioned sagging effect of ropes.

\section{Formulation of the problem}

Thus, the task of research is to compare means of computer simulation of the dynamics of an electric drive, taking into account and without considering the nonlinearities of the mechanical part, namely, the effect of the sagging of the rope.

\section{Main material}

The main factor to consider when creating a mathematical description of a sagging rope model is the factor of its variable elasticity, depending on the size of sagging. It should be noted that for the sagging rope, Hooke's law is not enforced. When deducing, the basic equations of statics for the system in balance are used:

- the sum of the projections of all external forces on the coordinate axis is zero: $\Sigma X=0 ; \Sigma Y=0$;

- the sum of the torques of all external forces or their projections for any point is zero: $\Sigma M=0$.

Consider the part of the rope, cutting it at the lower point of $O$ and at any point $D$ with the coordinates $(\mathrm{x} ; \mathrm{y})$. The cut off parts of the rope replaced by the corresponding forces according to the method $[12,13]$ : the force $H$ acts at the lower point of the sagging curve, and at the point D - the force $T x$ (see Fig. 1).

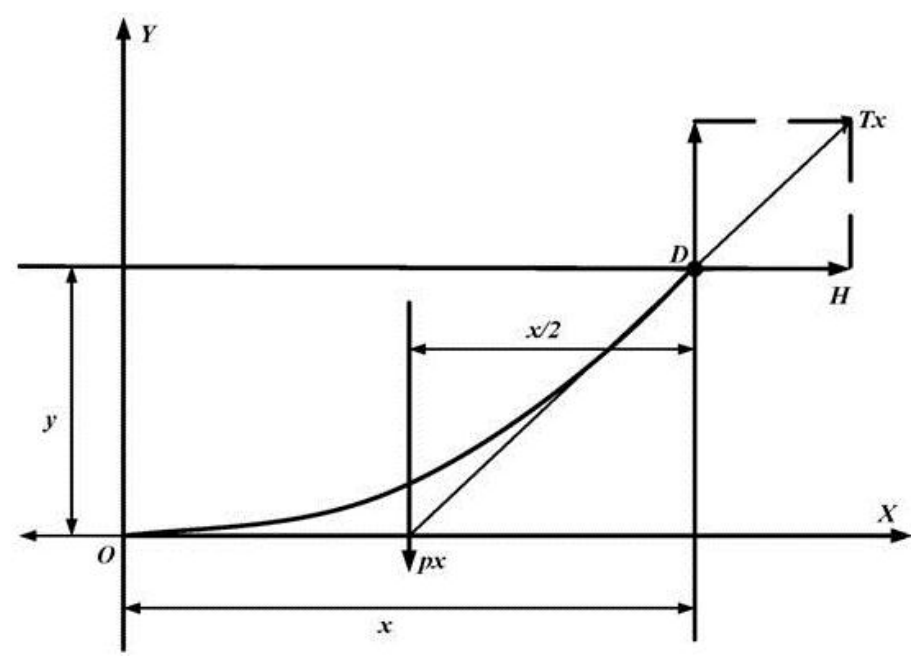

Fig. 1. External forces acting on the segment of the rope

For ropes, the tangent to the sagging curve at any point has a small angle with a horizontal straight line. This makes it possible to take the weight of this area evenly distributed horizontally and replace the concentrated force $p x$ acting in the middle of the considered section, that is, at a distance of $x / 2$ from the points $O$ and $D$. The force $T x$ is considered to be equal to the 
gravitational force at the lowest point $H$ (Fig. 1) according to [12, 13]. This assumes that the rope is an ideal flexible thread.

The direction of the force action of $H$ at point $D$ is opposite to the direction of the same force at the lowest point of the curve of the sagging rope, because of the properties of an ideal flexible thread; it can only work on stretching only. In this case, the equation of the forces of forces relative to point $\mathrm{D}$ is written as follows:

$$
\Sigma M_{D}=H \cdot y-p \cdot x \frac{x}{2}=H \cdot y-\frac{p \cdot x^{2}}{2}=0 \text {. }
$$

Having solved this equation with respect to the amount of sagging in, we obtain the basic equation of the curve of sagging of the rope $[12,13]$ :

$$
y=\frac{p \cdot x^{2}}{2 H}
$$

where $p$ - the unit load on the rope;

$H$ - gravity at the lower point of the sagging curve;

In practical calculations, not the force, but the tension in the rope $\sigma$, and not the single load, but the specific $-\gamma$ are used. Substituting in the previous formula $p=\gamma \mathrm{F}$ and $H=\sigma \mathrm{F}$, we obtain:

$$
y=\frac{p \cdot x^{2}}{2 H}=\frac{\gamma \cdot F \cdot x^{2}}{2 \sigma F}=\frac{\gamma \cdot x^{2}}{2 \sigma} .
$$

To determine the sagging arrow $f_{k}$ in the simplest case, namely, for the same height of the hanging points, we need to substitute the value of $x=1 / 2$ in formula (1), then we will have the value of the sagging arrow $f_{k}[14]$ :

$$
f_{k}=\frac{\gamma \cdot l^{2}}{8 \sigma}=\frac{T}{q \cdot l}
$$

where $q$-weight of the rope;

$T$ - force in the rope.

The rigidity of the "slack" from the sagging rope is determined by differentiation in length [15]: $C_{n k}=d \tau / d l=12 q f_{k}^{3}$. The stiffness of the rope, respectively, is a combination of linear stiffness (in accordance with Hooke's law) and a nonlinear component of the rope sagging, and will be in accordance with [15]:

$$
\frac{1}{C_{k}}=\frac{1}{C_{n k}}+\frac{1}{C_{l}} \quad \text { where } \quad C_{k}=C_{l} \frac{f_{k}^{3} \frac{12 q}{C_{l}}}{1+f_{k}^{3} \frac{12 q}{C_{l}}}
$$

It should be noted that in the case of different heights of the hanging points, the sagging curve of the wire will be asymmetrical and the lower point of the sagging curve will not be in the middle of the passage, but closer to either point A or to point B. In this case, it is necessary to determine three different types of arrows of sagging:

1) $f_{c}$ - the sagging arrow is in the middle of the span and can calculate by the formula $(2)$ for the arrow of sagging at the same height of the points of the suspension of the wire;

2) $f_{a}$ - the sag of the wire, which is measured relative to the ordinate of the lower point $\mathrm{A}$ of the suspension, is given by the formula: 


$$
f_{a}=\frac{\gamma \cdot a^{2}}{8 \sigma},
$$

3) $f_{b}$ - the sagging wire of the wire, which is measured relative to the ordinate of the highest point of the footing $\mathrm{B}$, is calculated by the formula:

$$
f_{b}=\frac{\gamma \cdot b^{2}}{8 \sigma}
$$

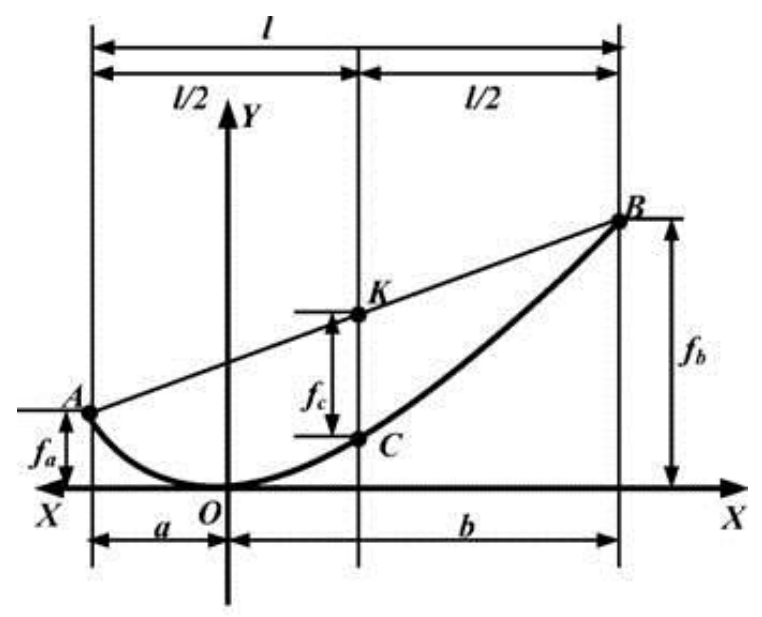

Fig. 2. Curve of sagging rope with different height of suspension points

As can be seen from the obtained formulas (3) - (5), the description of the sagging ropes is a rather complicated mathematical problem, therefore, in the first stage of computer modeling, it will be logical to use a simplification. In connection with this, for the used in the article computer models of the mechanical part, the following assumptions adopted:

- the rope is elastic and subject to Hooke's law;

- the rope is the perfect thread;

- the rope has the same suspension points.

In this case, the structural model of the rope stiffness variable due to its sagging based on formula (3) and will have the implementation shown in Fig. 3. The specific values of the model parameters correspond to the hoist drive of the Soviet excavator-dragline EШ-15/90 as example.

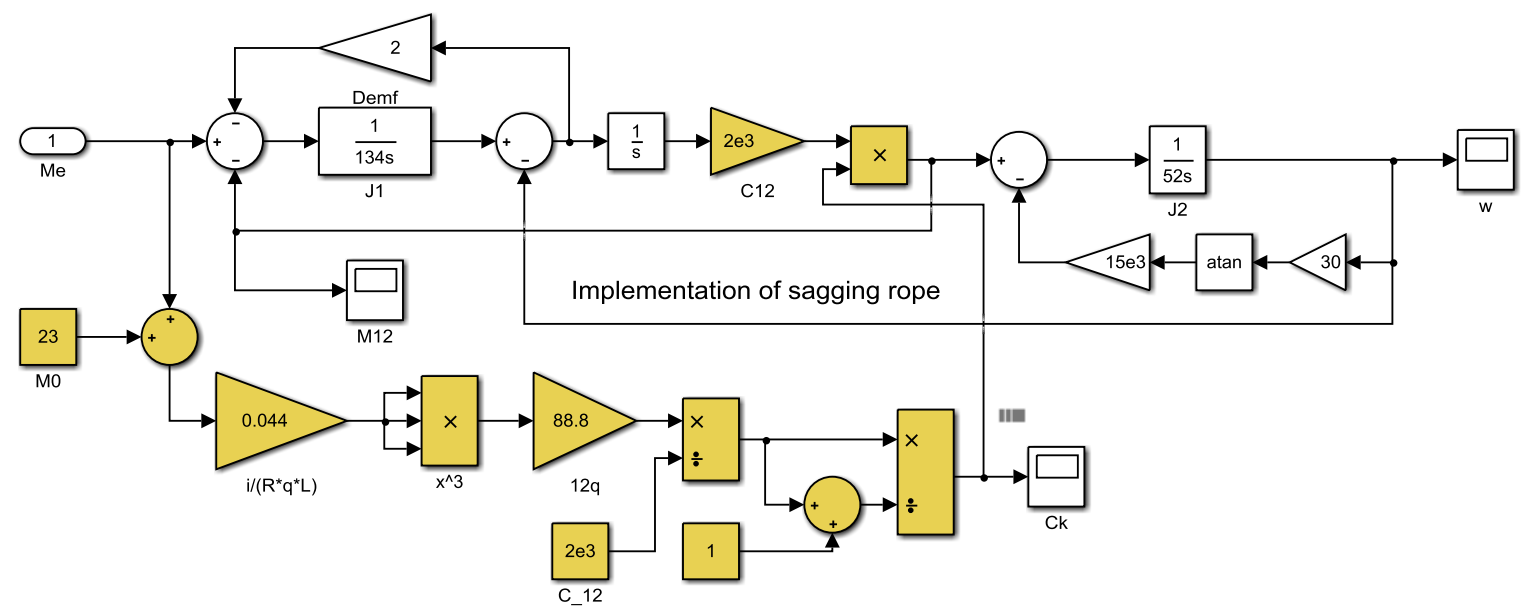

Fig. 3. Implementation of the computer model of the sagging rope by the formula (3)

For comparison of dynamic properties, a standard two-mass model of the hoist drive with constant elasticity is used, which is realized according to the well-known method $[10,11,16]$, 
and therefore, it is not shown separately to save space. The assumptions adopted for the model of the electric drive of the excavator-dragline EШ-15/90, which based on the Ward-Leonard system with magnetic amplifiers, are traditional [16]. Such a simplification of the models of the drive elements explained by the purpose of research - the difference in the behavior of two types of models of the mechanical part of the dragline drive researched. The traditional linear and taking into account the sagging of the rope by the method [15] studied as the easiest in the first stage of research, as already reported above. In both models, the same models of lifting electrons are used with the same task and load, however the difference lies in the implementation of models of the mechanical part.

Using the developed computer model, the process of starting the lifting of the bucket of the excavator-dragline, including the moment of its separation from the ground, explored. The resulting transients plotted and one of them (relative stiffness of the rope) shown below in Fig. 4. In particular, the graph of the relative elasticity of rope was interesting for analysis. There is that the effect of the rope sagging in this model is present only in the initial stage of the start, when the "weakness" of the rope was taken. Accordingly, further models of both systems behave in the same way.

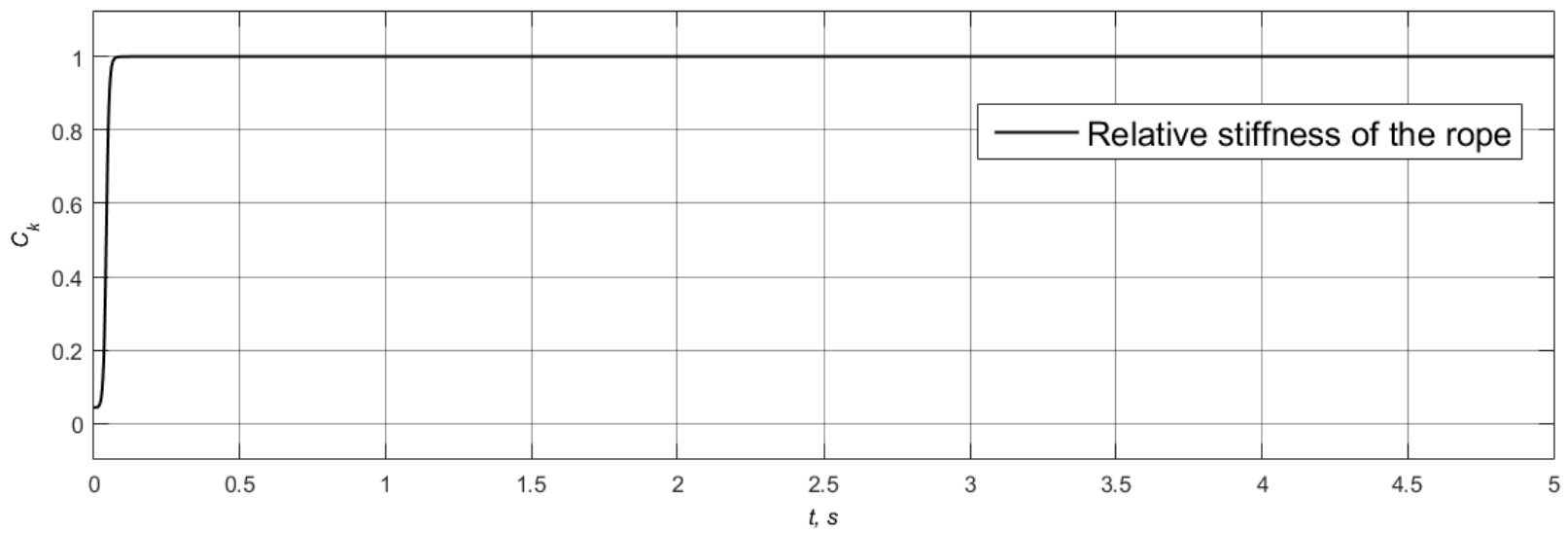

Fig. 4. A graph of the relative elasticity (stiffness) of the rope during the start

The analysis of the obtained results of the research showed that the option of taking into account the sagging effect in [15] in the case of its application to the drive of raising the dragline excavator is ineffective in terms of increasing the accuracy of reproduction of transients. Despite the noticeable complication of the cable system model (see Fig. 3), differences in the behavior of both methods of its simulation were not found, which is explained by the rapid process of selecting the rope slack in the model of the drive, after which the mechanical systems already have a similar behavior .

\section{Conclusions}

The application of the simplified model of the rope sagging by the method [15] leads to an unjustified complication of the computer model without the expected effect of increasing accuracy. Thus, it is possible to consider the use of a linear model of the rope drives without justification of the sagging effect of the rope.

\section{References}

[1] Grishina T.F. "Opredelenye peredatochnoi funktsyy lyneinoi systemы po kryvoi perekhodnoho protsessa" ["Determination of the transfer function of a linear system on the 
curve of the transition process"], Electromechanica - Electromechanics. - 1969. - No. 7. Pp. 762-768.

[2] Moroz V. "Numerical integrators in digital control systems." Bulletin of the National University "Lviv Polytechnic" "Electric power and electromechanical systems", 2006, No. 563, Pp. 99-104.

[3] Moroz V. "Analysis of the rational order of approximation for the restoration of information at its discrete readings." RIU (Radioelectronics, Informatics, Control), No. 1(19), pp. 74-78, 2008.

[4] Forsythe, G. E., Malcolm, MA, Moler, C. B. Computer Methods for Mathematical Computations. Englewood Cliffs, New Jersey 07632. Prentice Hall, Inc., 1977. XI, 259 pp.

[5] Numerical Computing with MATLAB by Cleve Moler. Online Resources. https://www.mathworks.com/moler/index_ncm.html.

[6] Leon O. Chua, Pen-Min Lin. Computer-Aided Analysis of Electronic Circuits: Algorithms and Computational Techniques (Prentice-Hall series in electrical \& computer engineering). 1st edition. Prentice-Hall, Englewood Cliffs, N.J., 1977. - 737 pp. [ISBN-13: 9780131654150].

[7] Controls and Experiments: Lessons Learned [A. Alleyne, S. Brennan, B. Rasmussen and others] // IEEE Control Systems Magazine. - 2003 - October. - pp 20-34

[8] Ignatiev S.A. "Research of rational modes of work of dragline excavators", Dissertation for the degree of candidate of technical sciences. Specialty 05.05.06 - "Mining machines". St. Petersburg, 1998, p. 146.

[9] Vologin N.A. "Improvement of control systems of electric drives of direct current of main mechanisms of career excavators. Specialty 05.09.03 - "Electrotechnical complexes and systems". Dissertation for the degree of candidate of technical sciences. St.-Petersburg 2003, pp. 178.

[10] Pevzner L.D., Babakov S.E. "Modelyrovanye y upravlenye operatsyei transportyrovanyia ekskavatora-mekhlopaty" ["Simulation and control of the transport operation of the mining excavator"], Horny ynformatsyonno-analytycheskyi biulleten - Mining information and analytical bulletin (scientific and technical journal). - 2015 - No.2. - Pp. 207-222. ISSN 0236-1493.

[11] Solovjev S. V. "Justification and choice of dynamic parameters of drive of traction mechanism of dragline". Specialty 05.05.06 - Mining machines, Dissertation for the degree of candidate of technical sciences. Moscow 2016, p. 116.

[12] Kachurin V.K., Bragin A.V., Erunov B.G. "Proektyrovanye vysiachykh y vantovykh mostov" ["Design of hanging and cable bridges"], Moscow: Book on Demand, P. 279.

[13] "Postroenye kryvoi provysanyia y opredelenye strel provysanyia" ["Construction of the sagging curve and the determination of arrows for sagging"] - Internet: http://leg.co.ua/knigi/oborudovanie/proektirovanie-mehanicheskoy-chasti-vl-4.html [Oct., 2018].

[14] Tauber B. A. "Pod'emno-transportnye mashyny" ["Lifting-transport vehicles: Textbook for high schools"], $5^{\text {th }}$ ed. - M .: Ecology, 1991, p. 528

[15] Shustov A.D. "Protsessy deformatsyy bumazhnoho polotna" ["Processes of strain of a paper webbing"], M., Lesnaia promyshlenost - Forestry, 1969.

[16] Kostynyuk L., Moroz V., Paranchhuk Ya. "Modeliuvannia elektropryvodiv" ["Electric drives simulation: Textbook"], L'viv, National University "Lviv Polytechnic" Publishing House, 2004, - P. 404. 